Journal of Animal and Veterinary Advances 11 (19): 3531-3534, 2012

ISSN: $1680-5593$

(C) Medwell Journals, 2012

\title{
Evaluation of Amitraz (C19H23N3) Stability Through Analysis with FT-IR Spectroscopy
}

\author{
Thiago M.B. Farias, Jose C.C. Santana and Felipe A. Calarge \\ Programa de Mestrado em Engenharia de Producao, Universidade Nove de Julho, Uninove, Brazil
}

\begin{abstract}
Given the prominent position of Brazil as the largest exporter of beef the veterinary market for medicines is expanding with an increasing demand for new products which have to improve their efficacy as well as to meet the regulations in terms of food security and environmental preservation. However, considering the acaracides management in order to control the parasites infestation it is verified several problems ranging from the incorrect dosage in the product application to the improper condition of storage. In this process analytical methods need to be developed and validated to meet the demands of national and international regulatory agencies regarding registration of these products not only for adequate quality control of veterinary products as well as guarantee of food security conditions to consumers and preservation of environmental conditions on the use of these products. This study aims to study the stability of amitraz (C19H23N23) in veterinary products through the technique of analysis by infrared spectroscopy and Fourier Transform (FT-IR). The results and limitations of this method were investigated by analyzing the spectroscopic changes occurring inside and on the surface of the material and also is presented the sensitivity levels of the active principle as well as the small structural changes that may occur in the material.
\end{abstract}

Key words: Stability evaluation, Amitraz, FT-IR, spectroscopy, acaricides, veterinary market

\section{INTRODUCTION}

The chemical and the pharmaceutical industry have over the time ensuring a key role in the process of products development and there are techniques that assist in directing the way forward and methodologies for the analysis of a product are essential tools facing a market as crowded and narrow (Versieck and Cornelis, 1980).

It is understood by veterinary medicine every chemical, biological, biotechnological substance manufactured which administration is applied individually or collectively, directly or mixed with food, for the prevention, diagnosis, cure or treatment of animal diseases. It can include additives, supplies, promoters, enhancers of animal production, antiseptics, disinfectants for in their environmental use or equipments, pesticides and all products used in animals and/or its habitat, protect, restore or modify their physiological functions and physiological as well as products for the beautification of the animals.

Among the veterinary medicines the tick pesticide noteworthy and the mainly groups of chemicals components that act as pesticides stand out arsenic, chlorine, carbamates, organophosphates, pyrethroids, formamidine, fluazuron, fipronil and avermectin.
Since, it became an economic problem for the livestock causing weight loss by the animal lower milk production losses to the leather weakening that leads to widespread predisposition to disease and others problems the chemical pesticides have been a major instrument of management of the cattle tick populations.

In Brazil, the utilization of acaricides for control of cattle tick populations is the most employed method and this practice has to be conducted under supervision in order to prolong useful life of the chemical pesticide and also to improve the product efficacy in different stages of this tick life-cycle (Bicalho et al., 2001).

However, the toxicological behavior of the thick populations can be different according the active ingredient in the commercial product and it is necessary a biological evaluation of alternative acaricides as well as to standard and validate diagnostic methods to detect tick populations resistance (Fernandes, 2000).

According to Fernandes (2001), the increasing loss of effectiveness of acaricides shows the necessity of monitoring of susceptibility levels and rational application improving the use of alternative control measures with lower environmental impact.

The correct utilization as well as the adequate management of the acaricides is essential to control the

Corresponding Author: Thiago Michel Brito Farias, Programa de Mestrado em Engenharia de Producao/UNINOVE/ Av. Francisco Matarazzo, 612, Predio C/1 Andar, Campus Memorial, CEP:05001-100, Sao Paulo, SP, Brazil 
tick population, being necessary in this way knowledge of the parasite biological cycle conditions for the proper dosage of the product and keeping the product under appropriate storage conditions.

Regarding the storage conditions of the product the environmental conditions considering temperature and humidity are considered the main factors influencing the shelf life which is determined in terms of the stability of the chemical components of the product. Stability can be understood as the product's ability to keep the original features considering the specifications for concentration, quality and efficacy.

For the product approval regardless for veterinary use, several tests are needed for analysis of similarity and stability, aims to prove that the amount of the active content remains close in different production batches. In this study, 3 sequential batches are produced and performed chromatographic analysis of content of active principle by applying the validated method, maintaining values close to each other. One of the lots analyzed is incubated in a climatic chamber and conduct will be the accelerated stability study of 6 months $\left(40^{\circ} \mathrm{C}\right.$ and $75 \% \mathrm{RH})$ and the study of long-term stability 24 months $\left(30^{\circ} \mathrm{C}\right.$ and $\left.65 \% \mathrm{RH}\right)$.

The spectroscopic techniques can be considered methodologies that assist in the product development process characterized by studies of highly oriented principles and procedures. When a mixture of chemical elements for a drug production is performed each element has their structural properties altered significantly and that change may user loss of activity as the appearance of toxicity in the mixture that is why is necessary to study all the consequences of it. The concentration of a solution is conditional on factors like the type of degradation (hydrolysis, oxidation or photolysis) and even the reaction speed.

The use of spectroscopic techniques became widespread in veterinarymedicine. As Kandemir et al. (2010) using techniques such as mass spectroscopy (ICP) can bring several information specially for the determination of heavy metals in Cyprinus carpio L., for the determination of florfenicol concentration in animals serum (Anderson et al., 2003) or in determining the stability of oxidizing components in meat (Onibi, 2003).

Veterinary products may have their stability affected by destructive processes both in the hydrolysis in which they interact with water molecules to form products with different chemical composition relative a oxidation which destroys many types of drug molecules occurring change in its color organoleptic properties and precipitation. The hydrolysis process is probably the main cause of decomposition of the drug since a large number of it active ingredients comprises esters where are susceptible to the hydrolytic process.

Thus, the objective of this study is to analyze the degradation of a drug in a product for veterinary utilization whose active ingredient is known commercially as Amitraz $\mathrm{C} 19 \mathrm{H} 23 \mathrm{~N} 3$ by spectroscopic and demonstrate that the degradation is directly involved with the improper handling or storage of the drug. In this sense, qualitative studies and spectroscopic analysis as well as simulations of physical weathering actions (temperature variations and light effects) will be carried out in three different commercial brands of commercial products.

\section{MATERIALS AND METHODS}

For the work development it was used the spectroscopy technique and Fourier transform infrared-FT-IR with a Perkin Elmer FT-IR 3600. The technique of transmission FTIR-MIR (casting film) and FTIR-microscopy shows more clearly the structural changes because it does not have the reflection characteristic and also shows spectroscopic changes more subtle and may also be regarded as an attractive methodology to analyze materials, polyamides and others (Montaser, 1998). The potential and limitations of these methods will be investigated by analyzing the spectroscopic changes that occur inside and on the surface of materials as well as changes related to $\mathrm{NH}-\mathrm{CN}-\mathrm{C}=\mathrm{O}$ exposing the material to Ultraviolet (UV) through a $1200 \mathrm{~W}$ lamp.

The samples used were randomly chosen so that all three drugs are for veterinary use and having C19H23N3 as the active principle, known as Amitraz. The samples were classified as A1, A2 and A3 in order to preserve the trademark. Initially, spectra were acquired in FT-IR spectra taking these as initial.

The samples were divided in two batches. One them was wrapped in the commercial packaging and maintained in an environment away from the light, the other are was maintained in an environment with to ultraviolet light exposure in order to a exposure.

\section{RESULTS AND DISCUSSION}

After a period of 30 days FT-IR measurements of different brands we obtained the first measurement acquired was of the pucket spectrum (background) followed by the measurements of samples spectra. It is noted that each spectrum is composed of an average of 25 scans. As shown in Fig. 1-3, it's noticed that the active principle (which has a vibrational energy in the wavelength range of approximately $1330 \mathrm{~cm}^{-1}$ ) (Vandecasteele and Block, 1993). 


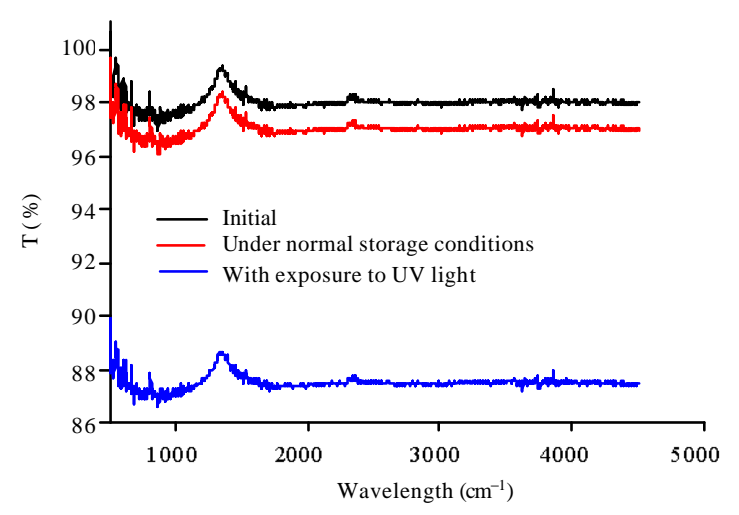

Fig. 1: FT-IR spectra for Sample A1

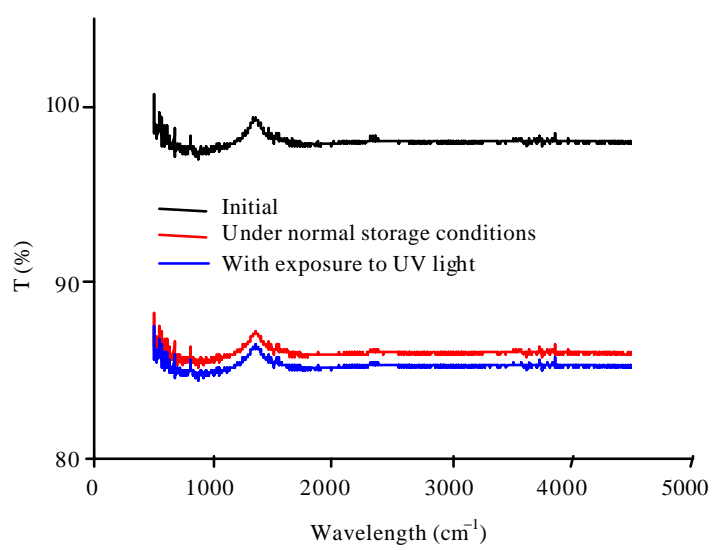

Fig. 2: FT-IR spectra for Sample A2

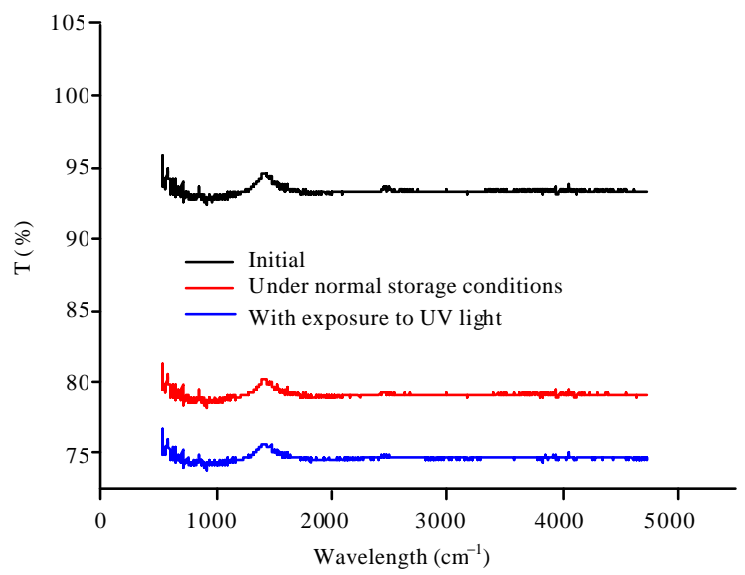

Fig. 3: FT-IR spectra for Sample A3

Both samples showed a decrease in their concentration as seen through transmittance intensity. This decrease originated storage as suggested by the manufacturer as well of by in storage with exposure to UV light. It is also noted in Fig. 4 the Sample 3 which has the

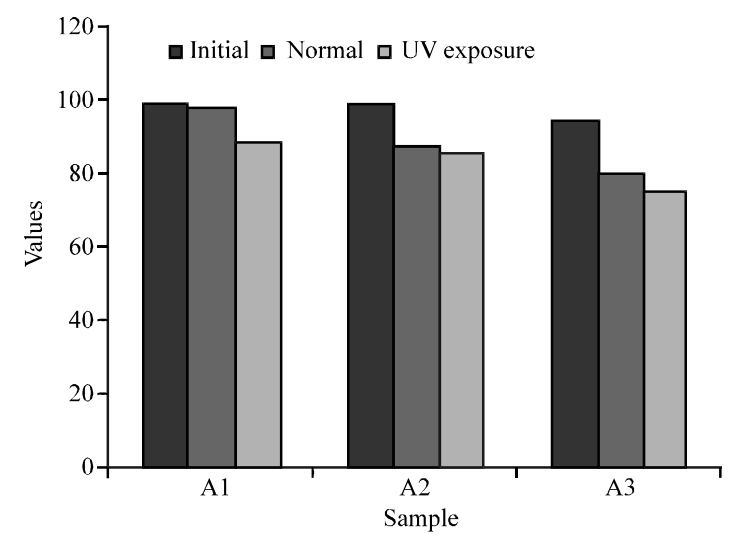

Fig. 4: Comparison of the relative amount of the active principle and initial storage of 30 days after

highest concentration showed the largest decrease with the relevant fact given that all samples should be diluted for use. The technique was sensitive to detect small structural changes occurring in the material that may suggest the formation of $3 / 4 \mathrm{OH}, \mathrm{HOC}=\mathrm{O}$ - and $-\mathrm{C}=\mathrm{O}$ and structural changes related to $\mathrm{NH}$ and $\mathrm{CN}-\mathrm{C}=\mathrm{O}$ groups. In the case of packaging it is noted that the plastic packages are formed by organic molecular structures not inert resulting in processes related to permeability removal and absorption or adsorption. The passage of the volatile constituents of certain drug molecules to the outside. Causes significant loss of its volume. In other cases the reverse may occur the contact of drug with oxygen and other molecules that pass from outside to inside can cause oxidation. PVC for example allowed the passage of molecules in the form of steam of $\mathrm{N}_{2}, \mathrm{O}_{2}, \mathrm{CO}_{2}$ and $\mathrm{H}_{2} \mathrm{O}$ thus causing a decrease in the concentration of the active principle of the samples.

The dispersion analysis in the environment was important since it is reported that equine sprayed with aqueous solutions of sulfur $0.2 \%$ showed marked neurologic signs similar to that received orally Amitraz (Dahlquist and Knoll, 1978). But there is no description of experiments that have used this concentration solutions $(0.2 \%)$. Studies show that amitraz is also harmful to pets like dogs and cats in general, presenting the same clinical signs of poisoning ranging from transient hyperglycemia to sedation, hypothermian and bradycardia bradyarrhythmia of different intensities.

Thus, its use in food should be done cautiously. According to the results obtained the application of amitraz in crops of apples 20 days before harvest does not guarantee its elimination in sufficient quantities to avoid the intoxication of consumers since almost $80 \%$ of product remains on the surface fruit so even contradict the vigilance agencies suggesting that foliar application 
has a security in an interval of 20 days with Acceptable Daily Intake (ADI) of $0.01 \mathrm{mg} \mathrm{kg}^{-1}$ bw (Barany et al., 2002).

The dilution should also be taken into account since the information that amitraz has agricultural indications as acaricide advocating its use in water although the literature data on ticks control guide diluting concentration of $10 \mathrm{~kg} / 1.000 \mathrm{~L}$ to stabilize the mixture $\mathrm{pH}$ 12 to prevent loss of action (Andrade et al., 2008; Duarte et al., 2003). It also may be noted that the higher the concentration of the active principle greater decline due to its storage and exposure to storms of nature.

\section{CONCLUSION}

The maximum concentration of pesticide residue legally permitted in foods is established by regulations of different countries. For Amitraz, the values should range between $0.01-10 \mathrm{mg} \mathrm{kg}^{-1}$. In Brazil, the Ministry of Agriculture, Livestock and Supply (MAPA), Amitraz included in the program control waste and contaminants (PNCR) in 2007. The program which was regulated by the Instruction on the 9th of March 30, 2007 provides for the implementation of analysis and determines the MRLs for various types of halogenated compounds organochlorines, carbamates, pyrethroids and organophosphates. According to the results obtained the application of Amitraz in crops of apples 20 days before harvest does not guarantee its elimination in sufficient quantities to avoid the intoxication of consumers since almost $80 \%$ of product remains on the surface fruit so even contradict the vigilance agencies suggesting that foliar application has a security in an interval of 20 days with Acceptable Daily Intake (ADI) of $0.01 \mathrm{mg} \mathrm{kg}^{-1} \mathrm{bw}$ (Barany et al., 2002).

The chemical control Amitraz is effective in this situation however, the emergence of resistance is inevitable. The intensive and failures in the management of acaricides accelerate the rate of evolution of resistance. So, in order to implement measures to slow the cumulative effect is necessary to know the extent of the problem and the reality of each region which applies amitraz ( $\mathrm{Li}$ et al., 2004).

\section{REFERENCES}

Anderson, A.C., B.D. Hunsaker, C. Duff, D.W. Walker and J.D. Roder, 2003. Florfenicol concentration in serum of beef cattle fed 0,3 or $6 \%$ added dietary fat in a $70 \%$ concentrate diet. J. Anim. Vet. Adv., 2: 44-48.

Andrade, S.J., C.B. Laposy, L.T. Rodrigues, J. Marcicano, C.V. de Andrade Jr. and T.L. Appel, 2008. Comparative study of experimental amitraz intoxication between dogs and cats. Braz. J. Vet. Res. Anim. Sci., 45: 17-23.
Barany, E., I.A. Bergdahl, L.E. Bratteby, T. Lundh and G. Samuelson et al., 2002. Relationships between trace element concentrations in human blood and serum. Toxicol. Lett., 134: 177-184.

Bicalho, K.A., F. Ferreira, L.M.F. Borges and M.F.B. Ribeiro, 2001. In vitro evaluation of the effects of some acaricides on life stages of Rhipicephalus sanguineus (Acari: Ixodidae). Arq. Bras. Med. Vet. Zootec., 53: 548-552.

Dahlquist, R.L. and J.W. Knoll, 1978. Inductively coupled plasma-atomic emission spectrometry: Analysis of biological materials and soils for major, trace and ultra-trace elements. Applied Spectrosc., 32: $1-30$.

Duarte, M.D., P.V. Peixoto, P.S. Bezerra Junior, K.D. De Oliveira, A.P. Loretti and C.H. Tojarnia, 2003. Natural and experimental poisoning by amitraz in horses and donkey: Clinical aspects. Pesq. Vet. Bras., 23: $105-118$.

Fernandes, F.F., 2000. In vitro activity of permethrin, cipermethrin and deltamethrin on larvae of Rhipicephalus sanguineus (Latreille, 1806) (Acari, Ixodidae). Arq. Bras. Med. Vet. Zootec., 52: 621-626.

Fernandes, F.F., 2001. Toxicological effects and resistance to pyrethroids in Boophilus microplus from Goias, Brazil. Arq. Bras. Med. Vet. Zootec., 53: 538-543.

Kandemir, S., M.I. Dogru, I. Orun, A. Dogru and L. Altas et al., 2010. Determination of heavy metal levels, oxidative status, biochemical and hematological parameters in Cyprinus carpio L., 1758 from Bafra (Samsun) fish lakes. J. Anim. Vet. Adv., 9: $617-622$.

Li, A.Y., R.B. Davey, R.J. Miller and J.E. George, 2004. Detection and characterization of Amitraz resistance in the Southern cattle tick, Boophilus microplus (Acari: Ixodidae). J. Med. Entomol., 41: 193-200.

Montaser, A., 1998. Inductively Coupled Plasma Mass Spectrometry. Wiley-VCH, Washington, DC., USA., ISBN-13: 9780471186205 , Pages: 964.

Onibi, G.E., 2003. Quality, sensory attributes and oxidative stability of some red meat under simulated open-market retail conditions in Nigeria. J. Anim. Vet. Adv., 2: 590-596.

Vandecasteele, C. and C.B. Block, 1993. Modern Methods for Trace Element Determination. 1st Edn., John Wiley and Sons Inc., Chichester, UK., ISBN-13: 978-0471940395, pp: 168.

Versieck, J. and R. Cornelis, 1980. Normal levels of trace elements in human blood plasma or serum. Anal. Chim. Acta, 116: 217-254. 